\title{
Rudolf Wiethölter Zur politischen Funktion des Rechts am eingerichteten und ausgeübten Gewerbebetrieb
}

$$
\text { I. }
$$

Das Recht am eingerichteten und ausgeübten Gewerbebetrieb (Recht am Unternehmen, Unternebmensrecht) wurzelt weder im Gesetz noch im Gewohnheitsrecht. Seinen Rückhalt findet es in einem Legendenrecht, das seit langem eine Domäne der Interessenten und Gutachter geworden ist, die sich jeweils eine schier unübersehbare Rechtsprechungsmasse gefügig machen. Die Rechtspreching reagiert auf diese Versuchungen in bizarrer Irrationalität. Sie gewährt im Arbeitsrecht, was sie im Presserecht verweigert. Sie entzieht dem Warentestrecht, was sie im Boykottrecht zugesteht. Wer genauer hinsieht, stellt freilich fest: die Rechtsprechung liebt eben die Pressefehde auf ihre besondere Weise, wie sie den Streik auf ihre besondere Weise nicht liebt. Sie schützt den Unternehmer als Eigentümer-Bürger auf ihre besondere Weise, wie sie den Nicht-Unternehmerund Nichteigentümer-Bürger auf ihre besondere Weise nicht schützt. Das Schrifttum akklamiert durchweg, kritisiert zuweilen isolierte Symptome oder abstrakte Begriffe und begründet Einwände fast stets dogmatisch, selten ökonomisch, nahezu nie politisch. Im ganzen: ein perfektes Spiegelbild eines individualistischunpolitisch-»rein « privatrechtlichen Rechtsverständnisses.

\section{1.}

Die Legende vom Recht am Unternehmen beginnt als reines Märchen: als Erzählung von etwas, das nicht wahr ist. Ursprünglicher Erzähler ist der I. Zivilsenat des Reichsgerichts in seinem Urreil vom 27. 2. 1904 (RGZ 58, 24-31). In diesem Fall hatte die Beklagte den Kläger aus drei eingetragenen Gebrauchsmustern in der üblichen Weise verwarnt. Der Kläger stellte die entsprechende Produktion ein, erreichte aber die Löschung der Gebrauchsmuster (wegen Schutzunfähigkeit) und verlangte dann Ersatz des aus Fabrikationsverbot und Strafanzeige erwachsenen Schadens. Das OLG Breslau wollte die Beklagte nur bei Kennenis ihrer fehlenden Gebrauchsmusterberechtigung, nicht schon bei fahrlässig fehlender Unkennenis verurteilen. Der r. Zivilsenat entschied in Anwendung von $\$ 823 \mathrm{I}$ $B G B$ zugunsten des Klägers. Begründung: Die Beklagte habe »aufgrund eines ihr nicht zukommenden Rechts, also objektiv widerrechtlich, in den bestehenden Geschäftsbetrieb des Klägers e eingegriffen. $Z$ war handele es sich nicht um »Beeinträchtigung seiner Eigentumsrechtex, weil die Einwirkung »nach Inhale und rechtlicher Bedeutung " dieselbe sei, auch wenn der Kläger seine Fabrikation niche auf eigenen, sondern auf fremden Stühlen betreibe. Entscheidend sei der ${ } \mathrm{Ge}-$ sichtspunkt des gestörten Gewerbebetriebes $\alpha$. Das RG lehnt ausdrüdklich ab, im 
Sinne von $\$ 823$ I BGB als "Rechrsgüter und Rechte « heranzuziehen: r. »die Verletzung der Freiheit« (als »freie Berärigung des Willens «), 2. »besondere Persönlichkeits- oder Individualitätsrechte" (so daß z. B. auch nicht etwa »die frcie Erwerbstätigkeit als solche, so wenig wie die Befugnis zu ungehinderter Verwertung der Arbeitskraft" unter $\$ 823$ I falle). Hingegen sei wan dem bereits eingerichteten und ausgeübten Gewerbebetrieb ein subjektives Recht « verschiedentlich angenommen worden, und zwar außer für negatorische $A b w e h r-a u c h$ für Schadenersatzansprüche. Das RG verweist in beiden Fällen auf Vorentscheidungen. Da negatorische Ansprüchc keinen Rückschluß auf den Rechtscharakter des geschürzten Gutes zulassen, lasse ich die entsprechenden Belegentscheidungen außer Betracht. Zum Schadenersatzrecht bezieht sich das RG auf RGZ 28, 228; 51,$66 ; 51,369 ; 56,27 \mathrm{r}$ und fügt hinzu:

"Der erkennende Senat glaubt sich grundsätzlich auf den gleichen Boden stellen zu sollen. Dadurci, daB es sich bei dem bestehenden selbständigen Gewerbeberriebe nicht bloß um die freie Willensberätigung des Gewerbetreibenden handelt, sondern dieser Wille darin bercits seine gegenständliche Verkörperung gefunden har, ist die feste Grundlage für die Annahme eines subjektiven Rechts an diesem Betriebe gegeben. Störungen und Beeinträchtigungen, welche sich unmitrelbar gegen den Gewerbebetrieb richten, dürfen deshalb als eine unter $\$ 823$ Abs. $x$ fallende Rechtsverletzung angesehen werden. Ein derartiger, gegen den Gewerbebetrieb selbst gerichterer Eingriff ist es offenbar, wenn aufgrund eines angeblich entgegenstehenden gewerblichen Schutzrechts die rechtliche Zulässigkeit dieses Betriebes in bestimmten Umfange verneint, und deshalb seine Einschränkung verlangt wird. Widerrechtlich aber ist dieser Eingriff, wenn das behauptere Schutzrecht in Wahrheit nicht bestehr, weil es sich dann nicht mehr um einen erlaubten Wettbewerb handelt. Das Gesetz stellt den Gewerbetreibenden unter bestimmten Voraussetzungen in der Gestalt des Patent- und Musterschutzes wertvolle Ausschließungsrechte zur Yerfügung, vermöge deren sie die Erzeugnisse ihrer Erfindungstätigkeit vor der Benurzung durch die gleichstrebende Konkurrenz sichern und ihrem eigenen Vorteil allein vorbehalten können. Es ist nur ein Korrelat zu dieser bevorzugten Stellung, daB sie auó für den Bestand des Rechts einzustehen haben, das sie zur selbstnützigen Beschränkung des an sich freien Gewerbeberriebes ihrer Gegner geltend machen, und nicht nur die Vorteile genießen, sondern auch die Gefahren tragen müssen, welche mit der Behauptung solcher ausschließlichen Patent- und Musterrechte verbunden sind.*

Ich bringe das ausführliche Zitat, um die Geburt einer Legende zu beleuchten. Denn I. sind alle Vorentscheidungen zum Schadenersatzrecht zu Unrecht benutzt worden. Und 2. tragen die eigenen Begründungen die These nicht.

ad $I$

a) In RGZ 28, 238 (I. Senat, 25. 6. I890; sechs Jahre vor dem UWG von I 896!) setzte sich im Falle einer Liefersperre durch eine Börsengenossenschaft das Kartell gegen die Gewerbefreiheit durch. Mit $\$ 823$ I BGB konnte sich das RG schon mangels BGB nicht befassen. Es entschied, daß bei gänzlicher Versorgungsabschließung eine rechtswidrige Vermögensbeschädigung anzunehmen sei, zwar nicht »an erworbenen Vermögensstücken * (lies: Eigentum!), wohl aber, weil das »Gewerbsvermögen « zur *Erhaltung und Nutzbarmachung * auf Außenbeziehungen angewiesen sei, die bei planmäßigem Abbau die Annahme einer vorsätzlich rechtswidrigen Vermögensbeschädigung gemäß $\ 8$ I 6 ALR; $\$ \int I I 6$, I2I, 773,774 Sächs. BGB rechtfertigten. Ferner sei heranzuziehen ein Recht wauf Wahrung des öffentlichen Ansehens individuellen Geschäftsbetriebs« gegenüber öffentlichen Verdikten, weil die „öffentliche Sperrung des Geschäftsverkehrs« durch die Genossenschaft *Zwangs- und Strafgewalt» ähnlich einer Zunft in Anspruch nehme zur Durchsetzung von Gesamtinteressen, für die eine Genossenschaft aber nicht zuständig sei. 
Wir sehen: Das RG hat hier kraft landesrechtlicher deliktischer Einzelnormen bei vorsätzlicher Vermögensbeschädigung Schadenersatz gewährt, indem es den Eigentumsschutz weiter entwickelt hat zu kommerzieller Betärigungsfreiheit und indem es Ehrenschutz betreibe durch Schadenersatzsankrion gegenüber Tat und Täter. Entscheidungskern ist, übersetzt in unsere heutige Normensprache, Diskriminierung (Bereich also von UWG und GWB!) und $₫ 826$ BGB. Die Ausdehnung von Eigentum zu kommerzieller Betätigungsfreiheit, die selbstverständlich, hätte das RG den Ansatz ernst genommen, später auf allgemeine Berufs- und Arbeitsentfaltung zu erstrecken gewesen wäre, starb indessen bald einen stillen Tod. In unserer Anfangsentscheidung RGZ 58 wurde dieser Gedanke ausdrücklich abgelchnt.

b) In RGZ SI, 66 (4. Senat, 6. 3. I g02) ist, wie sich lediglich aus einem Zitat in RGZ 5 I, 369 (374) ermitteln läßt (den Richtern muß also wohl ihre Rechtsentdeckung nicht als abdruckwürdig vorgekommen sein!), das »Recht auf Ausübung des Gewerbebetriebs« (in casu einer Privarkrankenanstalt) als durch $\int 823$ I BGB geschützt angesehen worden. $D a$ es um den Ausschluß aus einem Arzteverein ging, liegt die Vermutung nahe, daß in dieser Entscheidung kein kommerzielles Vermögensrecht, sondern ein berufliches Freiheitsrecht zur Debatte stand (ähnlich RGZ 28, 238, jedenfalls anders als in $R G Z$ 58, 24).

c) In RGZ SI, 369 (6. Senat, 29. 5. 1902) hatte im Zusammenhang mit einem Streik der Arbeitgeber Boykottbitten an seine Fabrikantenkollegen gerichter. Die Schadenersatzklage der Arbeiter wurde in drei Instanzen abgewiesen. Begründung: $₫ 823$ I BGB sei nicht betroffen; die Ehre falle nicht unter diese Bestimmung; die Ausübung des selbständig betriebenen Gewerbes »mag, namentlich insoweit dieselbe gegen gewisse Eingriffe Dritter durch die Vorschriften des Gesetzes zur Bekämpfung des unlaureren Wetrbewerbes vom 27. Mai I 896 besonders geschützt wird, als ein wohlerworbenes Recht anzusehen sein «. In casu seien aber lediglich Betätigung der Arbeitskraft und Erwerbsaussicht betroffen, also keine subjektiven Rechte. $\ 823$ II BGB (Beleidigung, Nachrede) und $\$ 824$ BGB seien nicht erfüllt. $\ 826$ BGB entfalle, weil der »Klassenkampf « freier Konkurrenzkampf sei, der nur bei Exzessen zu Schadensersarzplichten führen könne. Diesen Satz hat der BGH offenbar nie gelesen. Wir sehen ferner: das RG verlagert - in einem obiter dictum - den Gewerbeberrieb in das spezielle Wettbewerbsrecht. Incidenter hat es mit der Ablehnung der Schadenersatzklage den ursprünglichen deliktischen Freiheirsschurzgedanken schon aufgehoben.

d) In RGZ 56, 27 I (6. Senat, I4. I2. 1902) handelt es sich wiederum um eine Liefersperre durch einen Börsenverein. Das RG schreibe zum Gewerbeberrieb RGZ SI, 369 fast wörtlich $a b$, schließt jedenfalls bei Betätigung gewerblicher Handlungsfreiheit in der Konkurrenz oder in einer Koalition Rechtswidrigkeit aus und verweist auf den ausreichenden Rechtsschutz des Gewerbebetriebs in UWG, SS 823 II, 824, $826 \mathrm{BGB}$ (in casu hat es dann weder Ansprüche gemäß $\$ 6$ UWG noch gemäß $\$ 823$ II BGB als begründer angesehen). Wir sehen: Kein Wort vom Recht gemäß $₫ 823$ I. Im Gegenteil!

ad 2

Das RG (in $R G Z s 8,24$ ) beschlagnahme nicht nur zu Unrecht diese Vorentscheidungen, die, wenn und soweit sie überhaupt einschlägig sind, das Gegenteil der behaupteten Inhalte belegen. Das RG hat auch die eigene Behauptung nicht begründet. Diese Behauptung freilich ist aufschlußreich genug: Als Kern (»feste Grundlage $\alpha$ ) des subjektiven Rechts findet das RG den Willen des Gewerbebetreibenden, der im Gewerbebetrieb seine »gegenständliche Verkörperung « gefunden habe. Mit Hilfe dieser Konstruktion wird allgemeiner Eigentumsschutz 
auf speziellen Unternehmervermögensschutz ausgedehnt. Die Geburt privilegierten Unternehmerschutzes ist vollendet; denn wie könnte der Wille z. B. eines Arbeiters in ähnlicher Form »gegenständliche Verkörperung « finden? In Wahrheit ist für das RG das angegebene subjektive Recht nicht einmal die Entscheidungsgrundlage. Denn wirkliche Entscheidungsgrundlage ist das bei rechtlich unzulässiger Inanspruchnahme eines gewerblichen Schurzrechrs unerlaubte Wettbewerbsverbalten, gleichsam der Monopolrechtsmißbrauch, folglich ein Tatbestand des speziellen Rechts des Wettbewerbs und des gewerblichen Rechtsschutzes.

III.

Das Referat der irrationalen Anfänge des Unternehmensrechts rechtfertigt sich, weil ähnliche Entstehungszusammenhänge auch andere Legendenrechtsenrwicklungen tragen (ganz besonders im Arbeits- und Wirtschaftsdelikts- und -bereicherungsrecht) und weil die Lösungen aller bis heute umstrittenen Probleme von Beginn an falschen Kurs steuern. Ich erwähne:

r. Das Unternehmensrecht ist entstanden im Zusammenhang mit Wettbewerbsrecht. Dieses Wettbewerbsrecht blieb als Problem im Schatten, weil erst I 896 ein UWG entstand und weil angesichts der Kartellfreiheit in Deutschland die Gewerbef reiheit gegen Kartell- und Organisationszwang den kürzeren zog. Folglich wurde das Unternehmensrecht umso überflüssiger, je entwickelter sich das Wettbewerbsrecht darstellte. Freilich ließen sich die für wettbewerbsrechtliche Streitfälle benutzten Formulierungen später verwerten, um unter Abstrahierung von wettbewerbsrechtlichen Sachverhalten allgemeinen Vermögensschutz für Unternehmer zu produzieren.

2. Das Unternehmensrecht ist entwidklungsgeschichtlich eindeutig und einseitig an Eigentum (gegenständlich-räumlicher Geschäftsbereich!, der delikrisch am räumlich-gegenständlichen Bereich der Ehe orientierte Eheschutz weist also ebenfalls auf Eigentumsdenken hin!) orientiert, nicht an Freibeit und nicht an Person. Je enger der Eigentumsbegriff - z. B. durch Zerschneidung aller Verbindungslinien von »Arbeit« (überhaupt »Beruf«) zu "Eigentum « - auf Vermögensbesitz reduziert wurde, desto $z$ wingender wurde die Möglichkeit ausgeschlossen, jenseits des Unternehmerschutzes z. B. freie Berufe, Arbeiter, Landwirte, Organisationen (z. B. Gewerkschaften) ähnlich in ihren Vermögensinteressen zu schützen. Als z. B. der BGH im Jahre $1964\left(Z_{42}, 210\right)$ Gewerkschaften für parteifühig erklärte und die OTV gegen die Propaganda der Gewerkschaft der Polizei schützte, sprach er deshalb auch nicht etwa von einem Eingriff in den eingerichteten und ausgeübten Gewerkschaftsbetrieb, sondern von Beeinträchtigung des Mitgliederbestandes und des Wirkens der Gewerkschaft ( $\$ 823$ Abs. I BGB i. V. m. Art. 9 Abs. 3 GG*). Das allgemeine Persönlichkeitsrecht z. B. muß die Gewerbebetriebsstelle schlecint und recht vertreten. Zuweilen spricht man auch vom Recht am Arbeitsplatz usw. Die handelsrechtliche Entwicklung vom kaufmännischen $\mathrm{Ge}$ werbebetrieb zur Unternehmensorganisation, deren rechtliche Besonderheiten alle Fesseln des zu engen Kaufmannsrechts sprengen, ist im Deliktsrecht überhaupt noch nicht registriert worden, wenn man von speziellen GWB-Deliktsnormen absieht.

3. Spätestens seit 1909 , als ein modernes UWG (erstmals mit einer Generalklausel!) auf den Plan trat, ist der gesetzliche Notansatz des \$823 I BGB für den gewerblichen Deliktsschurz absterbereif. Die Entwicklung zog diese Konsequenz 
nicht. Sie machte aus der überholten Funktion des Unternehmensrechts einen Leertitcl, der inhaltlich buchstäblich nach "Belieben « valutiert wurde. Darin liegt die politische Funktion des Unternehmensrechts. Statt notwendiges Arbeits- und Wirtschaftsdeliktsrecht (UWG, GWB, Presserecht, Streikrecht, Boykottrecht usw.) aus dem privaten Deliktsrecht funktional und inhaltlich auszugliedern, siegten im Ergebnis die Bestrebungen, nichtprivate Spezialsachverhalte in das allgemeine private Deliktsrecht ( $\$ 823$ I BGB) zurückzuholen. Jüngst erklärte Fikentscher (in Festschrift Heinrich Kronstein, 1967, S. $261-304$ [272]), das Deliktsrecht sei mit dem UWG von 1909 einen "Irrweg « gegangen, $\$ 823$ I BGB habe die Führung übernehmen können und müssen. Hier steckt ein hochpolitisches allgemeines Problem: im Verhältnis von Privatrecht einerseits und Arbeits- und Wirtschaftsrecht andererseits erschließen sich wichtigste Aspekte des Verhältnisses von privat-wirtschaftlicher Macht und gesellschaftich-politischer Macht. Staat und Gesellschaft, öffentliches und privates Recht, Herrschaft und Arbeit, Verfassung und Privatrecht sind die zugehörigen Problemstichworte. Im Arbeits- und Wirtschaftsdeliktsrecht sind heute nicht mehr individual-privatrechtliche Grundlagen betroffen, also auf Individuen bezogene Rechtsformen, sondern politisch-verfassungsreditliche Grundlagen, also auf die Gesellschaft bezogene Rechtsfunktionen. Wer z. B. Arbeitsrecht oder Wirtschaftsrecht ins bürgerliche Privatrecht „zurückholen « will, holt in Wahrheit unsere als Aufgabe noch vor uns liegende politische Gesellschat in den hinter uns liegenden Obrigkeitsstaat zurück. Alle diese Tendenzen sind restaurativ. Das Arbeits- und Wirtschaftsrecht einschl. der entsprechenden Deliktsrechtsteile ließe sich schon heute leidlich modern als sozialwissenschaftlich strukturiertes normativ-regulatives System von juristischen Handlungsorientierungen konzipieren, die inhaltlich auf die vom Grundgesetz intendierte rechtsstaatlich verankerte soziale Demokratie bezogen sind. Das tradierte System des bürgerlichen Privatrechts (einschl. seines Deliktsrechts) versperrt hingegen einen solchen Zugang total. Denn während Privatrecht laissezfaire-Recht ist, also den einzelnen aus seinem »Eigentum " privat autonom leben läßt - und auf das Eigentum ist das System subjektiver Rechte exklusiv zugeschritten -, ist z. B. im UWG und im GWB public policy, „öffentliche Verwaltung * einer "guten Ordnung intendiert. Anders ausgedrückt: so wie im Privatárecht Individualinteressen um der individuellen "Freiheit" willen geschützt werden, so im Wettbewerbsrecht Allgemeininteressen um der allgemeinen "Freiheit « willen. Verfolgte $Z$ wecke und eingesetzte Mittel stehen im Privatrecht zur Disposition und zum Schutz der Individuen zur Verfügung, im Wettbewerbsrecht zur Disposition und zum Schutz der Gesellschaft. An die Stelle privaten Geschehens tritt öffentliches Gescheben. Angeblich unpolitisches Privatrecht wird durch politisches »Sozialrecht « abgelöst.

4. Der ursprüngliche Ansatz des Unternehmensrechtes (Eigentumsschutzerstreckung auf Unternehmervermögensschutz) ist aber nicht nur den verdienten Tod nicht gestorben, sondern ist im Entwichlungslauf erblüht zum Unternebmerpersönlichkeitsschutz: das Vermögen wurde durch einseitige Beschlagnahme der Menschenwürde gekrönt. Der Schutz jedweder unternehmerischer Betätigung ist nämlich nichts anderes als diese einseitige Verbuchung höchsten Verfassungsschutzes (Menschenwürde, Persönlichkeit) für »Unternehmer«. Dieser Entwicklungsgang weist eine skurril-kuriose $Z$ wischenetappe auf: etwa um 1930 trat in der Rechtsprechung in der systematischen Begründung des Unternehmensrechts an die Stelle des (oder neben das) Unternehmensrechts die Ableitung des Rechtsschutzes aus dem Persönlichkeitsrechesgedanken (Einzelheiten jetzt bei G. Schrauder, Wettbewerbsverstöße als Eingriffe in den eingerichteten und ausgeübten 
Gewerbebetrieb, 1970). Parallel damit verlief eine Umbuchung des Rechtsschutzes von $\$ I UWG, $\$ 826$ BGB in $\ 8_{23}$ I, $\ 1004$ BGB, weil alle beteiligren Kreise den Sittenwidrigkeitsstempel zu vermeiden suchten. Diese Veränderungen sind außerordentlich bedeutsam:

a) Obwohl lediglich "Taufakte vorgenommen werden sollten, erbrachte die Verschiebung von $\ 826$ zu $\ 823$ I BGB die Chance, fabrlässige Vermögensverletzungen entgegen den klaren Richtlinien des BGB mit Schadensersatzsanktionen auszustatten. Diese Chance hat dann vor allem die Rechtsprechung nach dem zweiten Weltkrieg in Streikfällen ausgenutzt, ohne sich um die TaufaktHistorie zu kümmern.

b) Die Persönlichkeitsrechtsorientierung im Gewerbeberriebsschutz kanalisierte Persönlichkeitsschutz in Richtung Unternehmervermögensschutz, ohne zu merken, daß seit dieser Weihe dem Unternehmer gleichsam eine deliktsrechtliche Monopolstellung eingeräumt wurde, deren Vermögensmonopolsituation mit Rücksicht auf die Uberhöhung zu Persönlichkeitsschutz insbesondere dann undurchschaut und unerörtert blieb, als und nachdem die kartellrechtliche Entwicklung rechtsgeschäftlich produzierte Monopole nicht mehr respektierte (vor allem also seit dem Alliierten Antitrustgesetzen und dem GWB von 1957). Mit anderen Worten: in einer Wirtschaftsrechtswelt, die sich als antimonopolistisch ausgibt, blieb das Unternehmen seiner Beförderung in die Persönlichkeitsrechtsphäre wegen geschürztes Monopol. Das war eine bemerkenswerte antimarktwirtsdrafliche Leistung, die sich an Stelle einer im Wege der Entmonopolisierung des Unternehmensrechtsschutzes schon längst überreifen Neuinterpretation von Unternehmensschutz nach $\$ 823$ I BGB hat erhalten können.

c) Die Persönlichkeitsrechtskomponente im Unternehmensrechtsschurz hat bis heure die Auseinandersetzung $z$ wischen sogenannter individualistischer und sog. institutioneller Interpretation des gesamten Wettbewerbsrechts verdunkelt und verhindert, daß die politischen Gehalte des Wirtschaftsrechts erkannt werden. Diese Verschieierung hat im Ergebnis politisches Wirtschaftsrecht als (angeblich) unpolitisches Privatrecht galvanisiert und ihren Höhepunke in der heutigen führenden neoliberalen Wirtschaftsrechtstheorie gefunden, die in geradezu scholastischer Weise ihr Verständnis von Privatrechtsordnung als Verfassungsrechtsordnung transzendiert.

d) Auf die Idee, daß, was als Persönlichkeitsrechtsschutz dem Unternehmer recht sei, anderen Berufen billig - mit anderen Worten, daß entweder der falsche einseitige Persönlichkeitsentwicklungszusammenhang aus dem Unternehmensrecht wieder gelöst oder aber auf alle Menschen in ihrer beruflichen Tätigkeit erstreckt - werden müsse, ist die Rechtsprechung nie gekommen, dafür aber ein Teil des Schriftrums, das sich z. B. für eine Art $»$ Recht an der Berufsausübung « ausspricht. Diese Gleichbehandlung klingt fortschrittlich, ist aber rückschrittlich. Denn sie sanktioniert vor allem die Zementierung eines umfassenden Schutzes der unternehmerischen Vermögensschutzinteressen, ohne in gleicher Weise ähnlich umfassenden Vermögensschutz anderer Menschen sichern zu können. Die Gleichbehandlung geht insbesondere an der modernen Entwicklung vom *privaten * zum nöffentlichen" (Arbeits- und Wirtschaftsrechts-) Deliktsrecht vorbei. Das "private " Deliktsrecht, das sich vom Strafrecht emanzipiert hat, also von seinen Lehren auch nicht mehr lebt, ist als $\otimes$ Wirtschaftsdeliktsrecht $\propto, \otimes$ Arbeitsdeliktsrecht« usw. eines der kompliziertesten und wichtigsten Rechtsgebiete geworden, in dem es um Macht, Kampf, Geld und Freiheit gleichermaßen geht. Das bedeutet heute vor allem: kein einziges Rechtsgur, erst recht kein Rechtsgut, das im zulässigen sozialen $*$ Kampf « eingesetzr ist und von ihm betroffen wird, verdient 
heute absoluten Rechesschutz, vielmehr muß das Unrecht eines Geschehens selbst erst -z. B. durch »Interessenabwägung «, durch Vergleich von $*$ Rechtsprinzipien * usw. - für jeden einzelnen Fall positiv, offen und deutlich begründet werden. Unternehmen sind eben in einer politisch und rechtlich »offenen Gesellschaft* keine absoluten Rechte. Den richtigen Ausgleich für Nichtunternehmer muß heute nicht ein Recht am Beruf übernehmen, sondern die Entfaltung des "Persönlichkeitsrechts. Es selbst freilich ist höchst problematisch. Dazu an dieser Stelle nur wenige Stichworte:

Wie man sich ein solches allgemeines Persönlichkeitsrecht vorzustellen hat, ist bis heute ungeklärt. Ais Recht der Persönlichkeit, an Persönlichkeit, auf Persönlichkeit, aus Persönlichkeit? Unklar ist schon, wie ais * Rechtsbegriff * Mensch, Person, Persönlichkeit zu sehen sind. Meist wird Person mit Rechtsfähigkeit identifiziert - damit wird Person als Rechtsbegriff überflüssig! - und Persönlichkeit als „Fortentwidklung « der Person, als »eine durch schöpferische Selbstentfaitung erreichte eigentümliche Verwirklichung des Menschenbiides« (H.Hubmann). Dieses Verständnis ist wesentlich urheberrechtilch geprägt, wie überhaupt das neue Urheberrechtsgesetz von 1965 ein juristisches Hohelied der Urheberpersönlichkeit (Urheber ist der Schöpfer des Werkes", so $\$ 7$ UrhG) geworden ist. Dabei ist historisch das Urheberrecht (also der Schutz der geistig-schöpferischen Leistung) außer auf die Persönlichkeit und ihr Recht auch auf das Eigentum und sein Recht gestützt worden, wie überhaupt entwicklungsgeschichtlich Eigentum und Persönlichkeit ebenso eng verbunden zu sehen sind wie Persönlichkeit und Geist. Müßte deshalb nicht ähnlich der Urheberpersönlichkeit die Unternehmerpersönlichkeit, die Arbeiterpersönlichkeit, die Eigentümerpersönlichkeit usw. ebenfalls herausragenden Rechtsschutz finden (die Erfinderpersönlichkeit findet ihn, wenn auch heute mit sehr umstrittenen Grenzen)? Wir sehen sofort: Hier ist mehr als nur der Mensch und die Person im Recht betroffen. Hier hat eine spezifische sozial-kulturelle Sondereinschätzung spezifischer Menschen, nämlich die des geistig-schöpferischen »deutschen Dichters und Denkers , bleibende - auch ökonomisch-politische - Auswirkungen gezeitigt. Der Künstler soberhalb « des Technikers, der Wissenschaftler »oberhalb $\alpha$ des Praktikers: Diese Gesellschaft hat ein Persönlichkeitsbild geprägt, das dem Grundgesetz heute zu Unrecht unterlegt wird. Die Grenzen des »individualistischen« Rechtsschutzes, der ganz sicher das private Leben aller Menschen streng sichern sollte, sind deshalb heute nur dann korrekt zu ermitteln, wenn diese falsche - ausschließlich geistig-philosophisch orientierte - Sicht der Persönlichkeit korrigiert wird. In dieser sozialen Dimension des Persönlichkeitsschutzes zeigen sich folglich auch die politischen Implikationen des Grundrechtsverständnisses.

Es fragt sich aber auch heute, was unter dem Segel des allgemeinen Persönlichkeitsrechts wirklich schützenswert ist. Als Herrschaftsrecht oder auch als Interessenrecht ist es nicht mehr verständlich zu machen. Es schützt den Menschen als Menschen. Je "privater « also seine gestörte menschliche Sphäre, desto massiver muß der Schutz sein. Je »kommerzieller « und »politischer « hingegen die gestörte Sphäre ist, desto weniger Schutz ist mit einem Persönlichkeitsrecht zu rechtfertigen. Wer sich z. B. auf seine verletzte Persönlichkeit beruft, weil er in einer Fernsehsendung als übier Denunziant im letzten Kriege, dessen Opfer aufs Schafott geriet, gezeigt wird, oder weil er für seine Rinderzucht sich nicht an genossenschaftliche Besamungsorganisationen halten will, oder weil er in einer Zeitung wahrheitsgetreu als korrupter Politiker geschildert wird - alles Fälle aus der Rechtsprechung -, beruft sich eben nicht auf schützenswerte Zonen privater, ungestörter menschlicher Existenz, sondern auf soziale, ökonomische, politische 
Interessen. Ein falsches Denken in Berechtigungen erschwert auf diesem Felde wie auch anderswo unsere juristischen Leistungen. Ein richtiges Denken in $»$ Prozessen " und "Institutionen " der politischen wie privaten Existenz heute könnte die Leitlinien für die Orientierung dagegen setzen. Persönlichkeitsschutz ist sicher kein leerer Wahn, aber unter ihm darf nicht Wirtschaftskampf oder Pressefreiheit begraben werden, von ihm darf niche Kommerzialisierung der menschlichen Würde gerechtfertigt werden. Umgekehrt wäre Ausdehnung des Persönlichkeitsrechtsschutzes vom rein geistig-schöpferischen Bereich auf den soliden Schutz der *Beleidigten und Erniedrigten« wie »Mühseligen und Beladenen « eine dankbare Aufgabe gerade für das Rechr.

Wir sehen: Vermögensschutz läßt sich nicht durch terminologische Frisur (Persönlichkeitsrechtsschutz) für Unternehmer und z. B. Arbeiter gleich betreiben. So wenig sich ein Persönlichkeitsrecht reduzieren darf auf matericile Eigentümer und spirituelle Urheber, so wenig darf es umgeliehrt hinter dem doch nur scheinbaren Anspruch der Gleichbehandlung aller Menschen überholte Formen von Vermögensschutz (Unternehmensrecht gemäB $\$ 823$ I BGB) versteinern. Der Sitz allgemeinen und gleichen Vermögensschutzes sind $\$ S 823$ II und 826 BGB.

5. Der Umstand, daB das RG gleich zu Beginn seiner Unternehmensrechtsprechung den Ansatz von der Betätigungsfreibeit abgeschnitten hat, indem es sich im Kern auf Eigentumsschutz zurückzog, hat gründlich verhindert, daß das wirkliche Problem auf diesem Felde je zur Debatte stand: nämlich die ökonomische, soziale, politische Auseinandersetzung in der Gesellschaft selbst und ihre deliktsrecistlichen Konsequenzen. Das RG hatte diesen Ansatz vor allem in der frühen Rechtsprechung wenigstens für seine Boykottrechtsprechung erhalten, und der BGH scheint insoweit, wenn auch in Grenzen, zu folgen, ein Zeichen, daß das RG damals zwischen Eigentum und politischer Auseinandersetzung zu unterscheiden wußte und diese Auseinandersetzung frei zu halten vermochte von nahezu automatischen und unvermeidlichen Schadenersarzfolgen. Es blieb dem Bundesarbeitsgericht vorbehalten, diesen freiheirlichen Entwicklungszug in der Streikrechtsprechung zu torpedieren. Heute besteht die Gefahr, daß im Zusammenhang mit Demonstrationen politische Grundgesetzfreiheiten auf der Strecke bleiben, weil sie mit Schadenersatzrecht erstickt werden.

Zusammenfassung:

Das Unternehmensrecht ist vom RG zum $Z$ wecke spezifisch relativierten Wettbewerbsrechtsschutzes geschaffen worden. Das RG hatte ihm zu Beginn ausdrücklich alle Freiheits- und alle Persönlichkeitsrechtselemente entzogen. Sein Kern war am Eigentumsschutz orientierter Unternebmer-Vermögensschutz in bestimmter wettbewerblicher Gestalt. Dieses Recht hat die Entwicklung des Wettbewerbsrechts bis heute nicht reflektiert, sondern negiert. Aufgeladen mit ursprünglich nicht inhaltlich gemeintem Persönlichkeitsrechtsdenken, hat es den einseitigen Unternehmerschurz unterschiedlich zu versteinern vermocht. Seine unkritische Entfaltung auf unterschiedlichen Rechtsgebieten hat zu seiner Leerformelfunktion geführt, die zugleich seine politische Funktion wurde. Sie läßt sich für die Gegenwart insbesondere an den Beispielen Wettbewerbsrecht, privates Deliktsrecht, Enteignungsrecht, Arbeitsrecht, Presserecht, Kritikrecht, Boykottrecht belegen, die den Hintergrund für die ungeklärten, anstehenden schadenersatzrechtlichen Probleme des modernen politischen Demonstrationsrechts bilden. 
r. Im Wettbewerbsrecht - genauer: im deliktsrechtlich relevanten Recht wettbewerblich orientierter Auseinandersetzungen - ist das Unternehmensredht tot. Rechtsschucz finden heute jeweils spezifische Vermögensinteressen gegen jeweils spezifische recheswidrige Handlungsweisen. Bürgerlichrechtlich-systematisch formuliert: die Probleme ankern - von $\$ 826$ BGB abgesehen - in $\$ 823$ II BGB, ohne daß es in der Regel der Fälle dieser allgemeinen Vorschrift noch bedarf (kanalisierter Vermögensinteressenschutz, nicht globalisierter (absoluter) Rechtsschutz!). Ein Unternchmensrecht gemäß $\$ 823$ I BGB geistert zwar zuweilen noch durch die Ziticrketten, aber nur als formale Zierde, mithin als obiter dictumLippenbekenntnis, nicht als ratio decidendi. Die rechtlich entscheidende Argumentation orientiert sich auf diesem Felde nicht mehr an Rechtszonen, sondern an der Mittel-Zweck-Relation der auf ihren Unrechtsgehalt jeweils zu überprüfenden Tathandlungen. Die rechtliche Argumentation verlagert sich vom verletzten (»absoluten «) Gegenstand zum Verletzungsgeschehen. Im Zentrum der Erör:erung steht mithin nicht die Automatik der Tatbestand-Rechtswidrigkeit-SchuldIndikationen, sondern die - ex post - Ermitrlung von Verhaltensregeln (Fandlungsanweisungen). Hier läßt sich im Ansatz eine sehr moderne Veränderung juristischer Arbeitsweise erkennen: von der juristisch-technischen Subsumtion zur sozialwissenschaftlich-technologisch-politischen Argumentation. Die Ablösung des individualistischen Rechtsformendenkens durch geselischaftlich bezogenes Rechtsfunkrionendenken wurde im Wettbewerbsrecht erleichtert durch Tendenzen, den Monopolcharakter subjektiver Rechte auf Wettbewerbsmärkten zu zerbrechen. Denn als deliktsrechtliches System bedeuten subjektive Rechte, daß eine - nur mit Hilfe von spezifischen Rechtfertigungsgründen widerlegliche Vermutung besteht, alle Interessenabwägungen zwischen Verletzer und Verletztem gingen zugunsten des Verletzten aus, eine marktwirtschaftich-wettbewerblich schlicht unhaltbare Vermutung. Stand hinter dem BGB-System von r 900 das Freiheitsethos der bürgerlichen Besizzklasse, so müßte vor dem BGB-System von I 970 das politische Ethos einer demokratischen Gesellschaft stehen. Unternehmerischer Vermögensschutz im Wettbewerb muß den argumentativen Weg einer an moderner Rechtstheorie und Rechtsmethodik orientierten Positivierung von kanalisierten Ersatzpflichten finden. Im wettbewerblichen Delikisrecht ist dieser Entwicklungsweg auch schon erstaunlich modern beschritten worden, als hätten hier gleichsam die Bedürfnisse der rivalisierenden Bewerber nach Arr moderner Urwüchsigkeit im Sinne wechselseitig ausgeglichenen give and take ihre passende Schadensersarzform schon gefunden. Das ließe sich im einzelnen mit der Rechtsprechung zum Behinderungswettbewerb, zur Ausbeutung, zur Preis- und Vertriebsbindung, zu Reklame und Kritik usw. belegen (das hat jüngst die angeführte Arbeit von G. Schrauder gründlich getan). $\$ 823$ I BGB (also das Unternehmensrecht selbst) führt auf dem wettbewerblichen Deliktsfelde kein eigenständiges Dasein mehr. Trotz der seit rd. 40 Jahren in der höchstrichterlichen Rechtsprechung zu findenden Erstreckung des Unternehmensrechtsschutzes von Bestands- auf Betätigungsschutz ist im wettbewerblichen Deliktsrecht der rechtswidrige Wettbewerb Kernelement des Schadensersatzrechts geblieben (sogar immer mehr geworden), folglich der Schadenersatzschutz im ganzen eher eingeschränkt als ausgedehnt wurde. Rechtspolitischer Hauptstreitpunkt ist unter dem rechtstechnischen Deckmantel der Interpretation z. B. von $\$$ I UWG (Stichwort: von der Sittenwidrigkeit zum ordre public!) der Verletztenschutz bei einfacher Verletzerfahrlässigkeit, d. h. die Risiko- und Chancenabgrenzung von 
monopolartigen Exklusivrechtszonen und wettbewerblicher Kampffreiheit. Auf $z$ wei kleineren Nebenfeldern scheint das Unternehmensrecht gemäß \823 I BGB noji niche endgültig tor zu sein: in der Verjährung ( $\$ 2$ II UWG i. V. zu $\$ 852$ $B G B$ ) und im Gerichtsstand ( $\$ 24$ UWG i. V. zu $\$ 32$ ZPO).

Ergebnis:

Das Unternehmensrecht ist im Wettbewerbsrecht entstanden und für das Wettbewerbsrecht einmal sinnvoil gewesen, im heutigen Wettbewerbsrecht aber überholt und tot. Seine außerwettbewerbliche Funktion, in der es nie wirklich höchstrichterliche und wissenschaftliche Begründung gefunden hat, ist als reine Rechtsideologie zugleich seine politische Funktion.

2. Im außerwettbewerblichen privaten Deliktsrecht (außerhalb also aller noch zu besprechenden Deliktrechtszonen!) hat sich das Unternehmensrecht im wesentlichen auf die Stromkabelunterbrechungsfälle zurückgezogen, denen das Schrifttum übertriebene Aufmerksamkeit zuwender, wobei es sich meist in dogmatischen Spielereien oderiund Spekulationen verliert. Der Obbergang vom Bestands- zum Betätigungsschutz im wettbewerblichen Unternehmensrecht vor rd. $40 \mathrm{Jahren}$ ist vom BGH im Jahre I95 I (BGHZ 3,270 - Constanze I) auf außerwettbewerbliche Fälle erstreckt worden, eine der bemerkenswertesten und folgenreichsten unkritischen Entscheidungsetappen unseres höchsten Zivilgerichts. Diese Entscheidung hat vor allem die Ablösung des uraiten kausalen Verständnisses des Unmittelbarkeitserfordernisses durch ein Unmittelbarkeitsverständnis i. S. von "Interessenabwägung" gebracht, und zwar zunächst noch auf der Rechtfertigungsebene (den heutigen Stand dieser Entwicklung präsentiert jetzt BGH JZ 1 968, 23 I [Nächte der Birgit Malmström]). Schon die frühere „Unmittelbarkeit « war stets eine Verschleierung des Umstandes, daß das Unternehmen eben doch nicht randlos als subjektives Recht verstanden wurde. Die moderne Interpretation von Unmittelbarkeit ist der endgültige Beweis dafür, daß es gerade nicht um Teilvoraussetzungen des Rechtsschutzes geht, sondern um die Begründung der Unrechtshandlung selbst, für die die "Unmittelbarkeit« nur ein reines Ersatzzauberwort abgibt, das die wirkliche Argumentation erspart oder ersetzt. Das wird deutlich an BGHZ 29, 65 (Kabelbruch I) im Verhältnis zu BGHZ 4r, I 23 (Kükeneier). In Z 29, 65 führte fahrlässige Stromunterbrechung nicht zu Schadenersatz wegen Unternehmensrechtverletzung gemäß $\$ 823$ I BGB, weil der Eingriff nicht gegen den »Betrieb als solchen gerichtet, also betriebsbezogen " gewesen sei (Stromlieferung sei keine $\gg$ wesenseigentümliche Eigenheit Unternehmens). In $Z_{4 \mathrm{I}}$, 123 führte fahrlässige Stromunterbrechung zu Schadenersatz wegen Eigentumsverletzung gemäß $\$ 823$ I BGB, weil der Eingriff sich gegen das Eigentum an den Kükeneiern gerichtet habe. Das ist - mit Verlaub reine Scholastik. Wer Küken aus Eiern produziert, kann nicht anders behandelt werden, als wer Stahl aus Eisenerz produziert oder Zeitungen aus Papier. Entweder genießen also alle diese Produzenten Unternehmensrechtsschutz oder keiner genießt Eigentumsschutz. Das Schrifftum will in der jüngsten Zeit allen den Unternehmensrechtsschutz gemäß $\$ 823$ I BGB zukommen lassen (z. B. jetzt Glückert in AcP I66 (1966), S: 311-329; Neumann-Duesberg in NJW 1968, 1990), zu Unrecht, wie ich meine. Denn hier wird der Kanalisationsgedanke ( $\$ 823$ II BGB) bei Vermögensschäden zugunsten der Unternehmer einseitig ausgeklammert. Hier wird die alte einseitige Verbindung von Unternehmerschutz und Eigentumsschutz galvanisiert, die seit RGZ \&8, 24 ausschließlich wettbewerbliche Orientierung hätte annehmen sollen und dürfen. Der Eigentumsschutz gemäß $\ 823$ I BGB deckt nicht Vermögensverlust infolge Produktionsausfalls. Der Kükenfall ist folglich ebenfalls ein Kabelbruchfall $\mathrm{I}$. $\mathrm{Ob}$ es richtig ist, in solchen 
Fällen die Schadenersatzpflicht von der Zufälligkeit landesrechtilicher Kabelrechtsnormen abhängig zu machen (vgl. BayObLG in NJW 1967, 364), lasse ich offen. M. E. handelt es sich um einen reinen Versicherungsrechtsfall.

Ergebnis:

Das Unternehmensrecht auf diesem Vermögensschutzfelde - die Rechtsprechung widmet ihm ausführliche und dogmatisch höchst modern klingende Lippenbekenntnisse - geht an Entwicklung und Lage des angeblichen Unternehmensrechts glatt vorbei. Die Leerformel von der Unmittelbarkeit (heute: »Betriebsbezogenheit ") zeigt, daß es dieses Recht in Wahrheit nie gegeben hat.

3. Im Enteignungsrecht hat sich das Unternehmensrecht ebenfalls nur scheinbar durchgesetzt, weil die entsprechenden Hinweise nur leere Entlehnungen aus dem Zivilrecht darstellen. Angesichts der Interpretation von Art. I4 GG wäre ein solches Recht auch völlig entbehrlich. Die wirklichen Begründungszusammenhänge beschäftigen sich deshaib mit dem Unternehmensrecht auch nicht ernstlich und entscheidend (vgl. jetzt $\mathrm{BGHZ}_{45}$, I so [Elbeleitdamm], BGHZ 49, $23 \mathrm{I}$ [Moselausbau]).

4. Im Arbeitsrecht wird die politische Funktion des Unternehmensrechts überdeutlich. Zur Einschätzung der Lage ist das Untersuchungsergebnis von Fikentscher (a. a. O., Festschrift Kronstein) hilfreich, der die Rechtsprechung analysiert hat und für die Fallgruppen der Beeinträchtigung des Unternehmens »durch Berufung auf außerwirtschaftiche Werte " folgendes Fazit zieht:

-Geht es darum, außerwirtschaftliche Werte mit dem Wert des Rechts am Gewerbebetrieb zu vergleichen, so verlassen den juristischen Betrachter nahezu alle Maßstäbe. Weder kann aus zunächst vorgehenden Sondergebieten die eine oder die andere Wertung entnommen werden, noch kann ein allgemeiner Gesichtspunkt wie der des Machtmißbrauchs Richtschnur sein. Wert steht gegen Wert, ohne daß zunächst eine Rangordnung dieser Werte aus der Rechtssphäre abgeleitet werden könnte.

Dennoch muß eine Entscheidung getroffen werden. Wenn man die dritte Fallgruppe betrachter, so gewinnt man den wohl auch sachlich zutreffenden Eindrudk, daB die Betonung bestimmter außerwirtschaftlicher Werte, wie politische Freiheiten, Meinungsfreiheit, religiöse Werte, im allgemeinen dem Interesse an ungestörter Unternehmensführung vorgezogen werden. Hierbei dürfte der Gedanke im Mirtelpunkt stehen, daß es im Gewerbebetricb im wesentlichen um Geldverdienst geht, wohingegen die Verwirklichung der geistigen Werte grundsätzlich eine gewisse bevorzugte Behandlung beanspruchen dürfen. Man darf daher, mit aller Vorsicht, als Regel aufstellen, daß die Berufung auf außerwirtschaftliche Werte gegenüber dem Recht am Gewerbebetricb grundsätzlich zulässig ist, so daß das Recht am Gewerbebetrieb zurïdkzutreten hat.

Davon sind aber aufgrund der hier geschilderten Fallgruppe zumindest drei wichtige Ausnahmen zu machen: (1) Im Arbeitsrecht ist der Eingriff in das Unternehmen rechtswidrig, wenn sich diese Rechtswidrigkeit aus arbeitsrechrlichen Grundsätzen ergibt. Dic Rechtswidrigkeit kann dabei im einzelnen im Verfassungsrecht beruhen, oder auch in der Betriebsverfassung. Hier sind Wertkonflikte, die in einern anderen Rectrsgebiet diskutiert werden, für die Beurteilung des zivilistischen Anspruchs aus $\ 823$ Abs. I maßgebend. (2) Ferner wird man die Wahrung der demokratischen Grundordnung grundsätzlich den hierfür zuständigen öffentlichen Organen zu überlassen haben. Es handelt sich um den gleichen Gedanken wie beim unzulässigen politischen Streik, der seine grundsätzliche Unzulässigkeit der Tatsache verdankt, daß er der verfassungsrechtlich gesicherten Willensbildung zuwiderläuft. Das gleiche muß auch gelten bei Wirtschaftsboykotten außerhalb des Arbeirsrechts. (3) Endlich erscheint die Einschränkung angebracht, daß die Berufung auf den außerwirtschaftlichen Wert niche unsachlich sein darf, und $d a ß$ dic mögliche Wertverwirklichung in keinem Mißverhältnis zur Schädigung des Gewerbebetriebes stehen darf. Dies ist die Iehre des Spätheimkehrerfalles (BGH 24, 200). Auch die Constanze-Doktrin, soweit sie nicht durch die Höllenfeuer-Entscheidung überholt ist, rechtfertigt sich auf dieser Grundlage.e 
In solcher Analyse treffen sich die folgenreiche Leerformelfunktion des Unternehmens und die folgenlose Lippenbekenntnisfunktion der waßßerwirtschaftlichen Werte.. Fikentscher hat dic wherrschende Meinung a leidlich zutreffend beschrieben. Die Regel-Ausnahne-Darstellungsheuristik wird dabei verdreht: Denn die Ausnahmen konstituieren ein nahezu ausnahmsloses Regelsystem, das höchstens im Presscrecht in jüngster Zeit zerbricht; entgegen Fikentscher hat nämlich die Höllenfeuer-Entschcidung die Constanze-Doktrin völlig überholt. Im Arbeitsrecht hatte das Reichsgericht - zum Teil in ausgesprochen politisch fortschritrlicher Weise - Schadenersatz an Streiks nur über $\$ 826$ BGB geknüpft. (Wichrigste Stationen in der Rechtsprechung: RGZ 51,$369 ; 64,52 ; 76,35 ; 140$, 423). Seit RGZ SI, 369 den Arbeitnehmern Schadenersatz gemäß $₫ 823$ I BGB verweigerte, konnte es keinen Schadenersatz gemäß $\$ 823$ I BGB für Arbeitgeber geben oder die Ersatzansprüche mußten auf Arbeitnehmer erstreckt werden. Das Bundesarbeitsgericht hat indessen das vom Reichsgericht zugunsten der Unternehmer-Eigentümer postulierte (aber außerhalb des Wettbewerbsrechts nie wirklich valutierte) Unternehmensrecht einseitig zugunsten der Arbeitgeber erstreckt. $\bowtie$ Arbeitskämpfe (Streik und Aussperrung) sind im allgemeinen unerwünscht, da sie volkswirtschaftliche Schäden mit sich bringen und den im Interesse der Gesamtheit liegenden sozialen Frieden beeinträchtigen «. (Großer Senat am 28. I. I955, BAGE I, 29 I-317 [300]). Den sozialpsychologischen Nährboden dieser Politik habe ich an anderer Stelle untersucht (Rechtswissenschaft, Fischer-Bücherei, Bd. 920, I968, S. 299 ff.). Das Bundesarbeitsgericht geht an der Deliktsrechtsentwicklung ebenso vorbei wie an der Verfassung des Bonner Grundgesetzes. Es kehrt Entwidklungen sogar wieder um, indem Strukturen galvanisiert werden, die schon im technischen Deliktsrecht längst tot waren. Das geschieht, indem im Arbeitskampf der Gewerbeberrieb des Arbeitgebers zu einem absoluten Recht i. S. von $\$ 823$ Abs. I BGB bef̈̈rdert wird, wodurch jeder Eingriff und jede Verletzung - und das ist selbstverständlich z. B. jeder Streik - zunächst als Unrecht gestempelt und eine mögliche Rechtfertigung (die nach dem System natürlich stets Ausnahme ist!) in der sozialen Adäquanz des Eingriffs geschafft wird. Mit dieser Doppelleistung, die in einer Zeit sterbender absoluter Rechte einseitig zu Gunsten von Arbeitgebern ein nie vorher gekanntes absolutes Recht postuliert und die mit einem bisher nie gekannten Rechtfertigungsgrund den Arbeitskampf nur ausnahmsweise legalisiert, wird die historische, politische und verfassungsrechtliche Verankerung und Sicherung des Arbeitskampfes privat delikesrechtlich wegeskamotiert. Diese Doppelleistung ist durch Rechtsgutachten vor allem des Arbeitsrechtlers H. C. Nipperdey vorbereitet und durch das Bundesarbeitsgericht, dessen I. Präsident Prof. Nipperdey war, durchgesetzt worden. Wiederum mit allem Respekt: Ich halte diese Doppelleistung schlicht für unhaltbar und rechtswidrig.

Die sog. soziale Adäquanz ist weder in der Lage, als Rechtfertigungsgrund die ihr zugedachten Funktionen zu übernehmen, noch - bei Uberwindung des falschen Verständnisses von Gewerbebetrieb als absolutem Recht - zu einer Rechtskategorie zu avancieren, die Unrecht im Einzelfall zu begründen vermöchte. Dann aber ist sie - nicht mehr, aber auch nicht weniger als - eine reine Leerformel ohne irgendeinen Gehalt. Sozialadäquat ist nach der ausdrücklichen Formel des Bundesarbeitsgericht, was nicht sozial inadäquat ist! Alle Hinweise auf die geschichtliche Ordnung des menschlichen Zusammenlebens, auf Sozialethik usw. füllen nicht die Formel an, sondern beschreiben lediglich mit anderen Worten noch einmal das Problem: Es geht hingegen um Begründungen für die Rechtmäßigkeit oder Rechtswidrigkeit von Arbeirskämpfen. Wer sagt, ein politischer 
Streik, cin wilder Streik sei rechtswidrig, weil er nicht sozialadäquat sei, sagt in Wahrheit: Dieser Streik ist rechtswidrig, weil er rechtswidrig ist! Die Sozialadäquanzformel löst mithin kein Problem, sie bezeichnet ein Problem (in unglücklicher, überflüssiger Terminologie überdies). Die Formel selbst entstammt dem Strafrecht und hat dort nach verbreiteter Auffassung die Funktion, Straftatbestände zu verengen, Strafbarkeit also einzuscbränken. Wer etwa als Arzt einen Patienten operiert, hat ihn nicht rechtswidrig am Körper verletzt, er hat, wie viele Strafrechtler dieses Ergebnis umschreiben, sozialadäquat (nämlich in seiner Funktion als Arzt!) gehandelt. Im Arbeirsdeliktsrecht - wie überhaupt im privaten Deliktsrecht - taugt hingegen die Formel nicht nur nicht, sondern sie erweitert sogar - entgegen ihrer Herkunftsfunktion! - die Deliktstatbestände, damit auch die Schadensersatzmöglichkeiten. Der freie Arbeitskampf wird so grundsätzlich schadensersatzpflichtiges Unrecht. Es fehlt die Zeit, im einzelnen auf Zusammenhänge der Formel mit ganz spezifischem Ordnungsdenken hinzuweisen, aus dem die Ergebnisse hergeleitet werden, die nach Verpackung in die Adäquanzformel dann scheinbar aus ihr wieder herausgepadkr werden. Dieses Ordnungsdenken ist, vorsichtig ausgedrüdr, nicht identisch mit der Verfassung des Bonner Grundgeserzes. Die Zauberformel von der sozialen Adäquanz gehört zu den Generalklauseln. Das - auch politische - Hauptproblem von Generalklauseln ist ihr instrumentaler Charakter: sie selbst in ihrer Leere sagen und leisten nichts, entscheidend ist, was mit ihnen als $*$ Vorwand $\propto$, von wem, in welcher Absicht, mit welchen Wirkungen gesagt und geleistet wird. Die Bedeutung solcher Generalklauseln für das Verhältnis vor allem von »Gesetz « und »Richter« liegt auf der Hand. Das Verhältnis greift tief in die Strukturen des Verfassungs-, Staars- und Gesellschaftslebens ein. Eine andere politische Bedeutung von Generalklauseln liegt darin, daß sie typischerweise aus politischen Kompromissen oder unerledigten Konflikten entstehen. Geradezu ein Dorado uneriedigter Konflikte und politischer Kompromisse bildet nun das Arbeitsrecht. Das heißt konkret: Vor allem die unerledigten Konflikte werden nicht rechtlich bewälrigt, sondern bleiben Konflikte, die sozial und politisch von den Konfliktsbereiligten erledigt werden, deren Siege, Niederlagen, Kompromisse, kommt es überhaupt zu Kampfentscheidungen vor und von Gerichten, rechtlich lediglich sanktioniert werden. Auf diese Weise stabilisiert die Zauberformel von der sozialen Adäquanz - in scheinbar rechtlicher Weise - soziale Machtverhältnisse. Eine Rechtsentscheidung ist nicht betroffen und kann auch nicht betroffen sein. Trifft zur sozialen Adäquanz als Kriterium für Recht oder Unrecht von Arbeitskämpfen noch hinzu das zweite Kriterium nach der Rechtsprediung des Bundesarbeitsgerichts, nämlich die rechtliche Uberzeugung, so gesellt sich zum sozialen Machtverhältnis das Bewußtsein der solche rechtliche Uberzeugung Verwaltenden, also der Juristen, vornehmlich der hohen Richter und einiger Gutachter-Professoren. Beide Grundlagen wirken sich unmittelbar z. B. im sog. politischen und wilden Streik aus.

Die soziale Adäquanz hat in Verbindung mit dem absoluten Recht des Gewerbebetriebes den deliktischen Rechtssdiutz im Arbeitsrecht von $\$ 826$ BGB zu $\$ 823$ I $B G B$ verlagert. Sachlich ist, wenn man erst den Stand des modernen Deliktsrechts erreicht hat, der Unterschied, von einer wichtigen Ausnahme abgesehen, an sich nicht sehr gewichtig. Denn die Unrechtsbegründung von Arbeitskampfgeschehen muß sich letzrlich in beiden Fällen orientieren an einer Methode, die Rechtstheorie in Rechtspraxis umsetzt und deshalb vor allem Mittel und Ziele rational vermittelt. Die wichtige Ausnahme liegt im Problem möglicher Irrtümer der Handelnden: gemäß $\int 826$ BGB trifft die Schadensersatzpflicht nur den, der vor- 
sätzlich gehandelt hat, die meisten Irrtümer schließen Vorsatz aus (der streikende Arbeitnehmer oder die Gewerkschaft glaubten z. B., sie handelten rechtmäßig!). Gemäß $\{823$ I BGB hingegen schließen Irrtümer nicht die Fahrlässigkeit aus, die nach dieser Vorschrift ebenfalls zu Schadenersatz verpflichter. Die Arr, wie Irrtumsrisiken im Arbeitskampfrecht - entgegen dem Irrtumsrecht in anderen Rechtsgebieten - einseitig zu Lasten der Arbeitnehmer verteilt werden, weist zusätzlich auf die Bedeutung der angewandten Vorschriften hin.

Daß sich die Gewerkschaften diese Arbeitskampfrechtsprechung haben gefallen lassen, trifft sie als Vorwurf, gehört freilich zu ihrer Entwicklung in einem Klima unpolitischer Sozialtaktik.

Ergebnis:

Das Unternehmensrecht ist per Trickrechtsprechung ins Arbeitsrecht eingezogen und dient ausschließlich als Anti-Streik-Waffe in einer Gesellschaft mit arbeitskampffeindlicher Bewußtseinsstruktur.

5. Im Presserecht hat im Anschluß an das Lüth-Urteil des Bundesverfassungsgerichts (BVerfGE 7, I98) die Rechtsprechung zum Deliktsrecht neben viel Vernunft auch viel Unsinn produziert. Den Höhepunkt des unsinnigen Entwicklungszweiges stellt das Blinkfüer-Urteil des BGH (JZ 64, 95 = NJW 64, 29, vom Bundesverfassungsgericht am 26.2.69 aufgehoben, NJW I969, I16I) dar. Die Blinkfüer-Entscheidung war nämlich keine Bevorzugung der Pressefreiheit vor Gewerbefreiheit, sondern eine Entscheidung gegen die *Berliner Mauer", eine Entscheidung zugleich für die Pressepolitik Springers im West-Ost-Konflikt. Die Entscheidung war schon deshalb falsch, weil der BGH zumindest Pressefreiheit gegen Pressefreiheit hätte »abwägen « und außerdem erkennen müssen, daß Springer ausschließlich Wirtschaftsboykott betrieb. Inzwischen ist durch die Höllenfeuer-Entscheidung (BGHZ 45, 296) das Presseterrain gründlich und fortschritrlich geklärt worden. Diese Entscheidung hat die folgenreiche ConstanzeDoktrin zerstört, den falschen Ansatz der Blinkfüer-Doktrin bereinigt, das deliktsrechrlich-technische Unrechtsindikationsdenken beseitigt und im Kern verfassungsrechtlich und gesellschaftspolitisch entschieden. Der Kernsatz, daß nur noch bösartige und gehässige Schmähkritik zum Schadenersatz führe, bedeutet nämlich deliktsrechtlich die Reduktion der Schadenersatznormen auf $\ 826$ BGB, bedeuter verfassungstechtlich die Gewährleistung der richterzensurfreien inhaltlichen Pressefreiheit und bedeuter politisch die Respektierung politischer Auseinandersetzungen unter ausschließlicher Kontrollzuständigkeit der »Offentlichkeit«, also der Gesellschaft selbst.

Ergebris:

Das Unternehmensrecht gem. $\$ 823$ I BGB ist im Presserecht tot.

6. Im Recht öffentlicher Kritik (außerhalb des Presserechts) ist nur äußerlich eine relativ kleine Fallgruppe betroffen (Tatsachenbehauptungen und Werturteile [z. B. Warentest!]). In Wirklichkeit hat diese Rechtszone Gewicht vor allem durch das, was sie nicht erfaßt. Denn abgesehen von Persönlichkeitsrechtschutzmöglichkeiten läßr sich die massierte Verletzung z. B. des seingerichteten und ausgeübren Meinungsberriebes* politischer Bürger der Bundesrepublik - und zwar nicht nur durch Springer - schlechterdings nicht erfassen. Hier zeigt sich eben die Kehrseite der politischen Medaille Unternehmensrecht (= Eigentümerrecht!). Das Unternehmensrecht schirmt nämlich - außer gegen Streik - vor allem gegen öffentliche Kritik ab. Hier ist heute das zweite Hauptfeld für $\$ 823$ I BGB, technisch vermittelt über $\$ 824 \mathrm{BGB}$ und seine Interpretation (dazu eindrucksvoll jüngst Kübler, JZ 68, 542 ff). Auch hier hat die Constanze-Doktrin gegen das Gesetz und gegen die Rechtsprechung neue Unternehmensschutzgrundsätze 
durchgesetzt, indem sie ohne Rücksicht auf das Grundgesetz (z. B. Art. s GG) selbst wahrheitsgemäße Tatsachenbehauptungen, wenn sie geschättsschädigend sind, zu rechtswidrigen Unternehmensrechtseingriffen (Folge zumindest: $\ 1004$ BGB) stempelte. Der Referentenentwurf eines neuen Schadensersatzrechts von I 967 hat die illiberale Rechtsprechung normativ eingefroren, will also durch Gesezzgebung die längst überholte Constanze-Doktrin verewigen. Der zuständige Referent im Bundesjustizministerium hat auf entsprechende Kritik geäußert (siehe den Hinweis in JZ 68, 573 f.), der Referentenentwurf sei vor der Höllenfeuer-Entscheidung formuliert worden. Dieser Hinweis wirft Licht auf das Verhältnis von Gesetzgebung und Rechtsprechung und hilft zugleich, den heutigen Gesetzesbegriff zu erarbeiten. Ist etwa Art. 20 III GG neu zu lesen: Die Gesetzgebung ist an die Rechtsprechung gebunden? Kübler hat zu Recht davon gesprochen, daß solche Kechtsprechung und solche Gesetzgebung die Fetische des Konsums zu offiziellen Götzen salben. Der Wirtschaftsprozeß wird hier von Kritik freigehalten.

Ergebnis:

Das Unternehmen wird außer gegen Streik auch gegen öffentliche Kritik in falscher Weise (\$823 I BGB statt $\$ 826$ BGB) abgeschirmt.

7. Im Boykottrecht war das Reichsgericht fortschrittlich. In RGZ 64, 52 (1906) wurde der Boykott (ähnlich dem Streik) als legaler *Lohn- und Klassenkampf * empfunden (guter Glaube an die Handlungsnorwendigkeit schließe auch einen Anspruch aus $\ 826$ BGB aus!); zum Unternehmensrecht wird nichts gesagt. In RGZ 76, 35 (1911) wird ein Fall des Ubermaßes an sich statthaften politischen Kampfes angenommen (die Entscheidung ankert in $\$ 826$, nicht 823 I BGB (s. S. ${ }_{46} 68$ f.)). In RGZ I 40,423 (1933) bleibt der politische Sachverhalt zwar dunkel, das Gericht befaßt sich aber eindeutig mit $\int 826 \mathrm{BGB}$, weil es $\ 823 \mathrm{I}$ $B G B$ nur sehr eingeschränkt für einschlägig hält. Der $B G H$ hat sich in seiner Boykotr-Rechesprechung in wettbewerblichen Deliktsfällen gegen $\ 823$ I BGB und für Wettbewerbsspezialrecht ausgesprochen (BGHZ 38,90$)$ und in außerwettbewerblichen Deliktsfällen die falsche Blinkfüer-Doktrin bisher nicht ausdrücklich aufgegeben, dazu aber auch noch keine Gelegenheit gehabt (implicite har das »Höllenfeuer « das „Blinkfüer « auch hier gelöscht). Immerhin-läßt die in der Blinkfüer-Entscheidung unbegründete These, 'der Boykott aus politischen Gründen und mit wirtschaftlichen Mitteln sei nicht grundsätzlich unzulässig, den Rückschluß auf die - m. E. begründete - These zu, daß der Boykott aus politischen Gründen mit politischen Mitteln erst recht zulässig ist. Freilich spukt hier die herrschende Meinung im Schriftum, die für die »zuständigen öffentlichen Organe* Exklusivrechte der Wahrung einer freiheitlichen demokratischen Grundordnung postuliert.

Ergebnis:

Im Boykottrecht ist das Unternehmensrecht tot, genauer: es hat hier nie gelebt.

$V$.

Das Boykottrecht (boykottieren kann mit Erfolg nur, wer jeweils smarktbeherrschende « Gewalt hat!) leitet über zur kompliziertesten und ungeklärtesten, weil erst seit kurzem aktuellen Problematik eines Unternehmensrechtsschutzes: Schadenersatz im Zusammenhang mit politischen Demonstrationen (Blockaden, Protest, Widerstand). Ich präsentiere meine Stellungnahme in Thesenform.

r. Die Vorstellung, für die Wahrung der freiheitlichen demokratischen Grundordnung gebe es exklusiv zuständige »öffentliche Organea, ist ebenso weit 
verbreitet wie verfassungswidrig. Thnlich wie z. B. im politischen Streikrecht hantiert sie vor allem mit einem Gesetzes- und Rechtsverständnis, das sich als Labands Identifizierung von Gesctz im materiellen Sinne und allgemcinem Rechtssatz entiarven läßr. Laband hatte auf diese Weise das historisch-politische Gesetzes- und Rechtsverständnis seiner eigenen Zeit mit dem abstrakt-theoretischen Gesetzes- und Rechtsverständnis aller Zeiten verknüptt und so sein Rechtsverständnis - nämlich die Mischung von Kant, A. Smith und Savigny - in Versteinerungsform vererbt. Politische Willensbildung und Rechtsbildung sind indessen heute nicht auf Parlamente kanalisierbar, sondern Prozesse öffentlicher Auseinandersetzung über Konflikt und Konsensus. Politische Demonstrationen sind ein Teil solcher Auseinandersetzungen. Sie haben sich vor allem am politischen Inhalt der Verfassung unserer Gesellschaft zu legitimieren.

2. Freilich fällt es unserem Recht und unseren Juristen schwer, das Kernproblem zutreffend zu beurteilen. Denn unsere Rechts- und Juristenwelt ist im ganzen vorindustriell, vordemokratisch, vorwissenschaftlich, kurzum: sie ist nicht auf der politischen Höhe unserer Zeit. Das Selbstverständnis unseres Rechts und unserer Juristen wird noch immer bestimmt von einem idealistisch-philosophischbürgerlich-liberalen Gesellschaftsmodell. Deshalb z. B. der Ruf nach $»$ Sicherheir und Ruhe! Ordnung und Freiheit! a allerorten. Dieser Ruf verkennt die sozialen und politischen Existenzbedingungen unseres pluralistisch-politisch-demokratisch-sozialen Zeitalters. Sicherheit, Ruhe, Ordnung und Freiheit sind heute nicht mehr Voraussetzung einer guten Einrichtung der Gesellschaft, wie der bürgerliche Liberalismus glaubte, sondern erst ihre mögliche Folge. Genau das ist der Kernunterschied $z$ wischen unserem Staat, den wir noch nicht geschaffen haben, und dem Staat des 19. Jahrhunderts, den wir noch nicht überwunden haben. Die politiscien Demonstrationen in unseren Tagen entlarven solche Zusammenhänge, weil sie nicht zulezzt die politische Natur des Rechts demonstrieren, die am meisten von denen geleugnet wird, denen diese politische Wirkung des Rechrs zugute kommt. Es geht nämlich heute nicht lediglich um ein modernes Strafrecht und Privatrecht, sondern um nicht weniger als unser Verfassungsverständnis selbst. Das Bonner Grundgesetz ist schließlich kein zeirloses Naturwunder. Unser Grundgesetz wurde vielmehr zu einseitig gegen eine falsch interpretierte $\mathrm{Ge}-$ schichte der Weimarer Verfassung konzipiert. Unter den sozialen und ökonomischen Verhältnissen seither hat seine lautlose Transformation die verheißene freiheitliche demokratische Grundordnung stärker entmutigt und gedrosselt als ermutigt und ermöglicht. Man muß die politischen Demonstrationen also auch rechtlich - z. B. verfassungsrechtlich, strafrechtlich, hier folglich deliktsrechtlich sehen als politische Anteilnahme und Anteilhabe an den verfassungsrechtlich wie verfassungspolitisch gewährleisteten Prozessen öffentlicher Auseinandersetzungen über Konflike und Konsensus in unserer Gesellschaft. Eine »friedliche«, eine sordentliche«, eine "ruhige« Demonstration entspricht einem überholten unpolitisch-liberalen Rechts- und Politikverständnis - der Bürger konnte danach $z$ war denken, was er wollte, aber er hatte zu gehorchen. Heute ist die »unruhige " und "unfriedliche" Demonstration ein Stüdk Verfassungswirklichkeit, sie gehört norwendig zum politischen und rechtlichen Leben unserer Gesellschaft. Das ist selbstverständlich kein Freibrief für Mord und Totschlag. Aber umgekehrt sind Geld- und Sachschäden durchweg von minderem Rang z. B. gegenüber politischer Aufklärung und politischer Kommunikation in Offentlichkeit, z. B. auch gegenüber dem Kampf um demokratische Pressefreiheit, kurzum: gegenüber politischer Arbeit an der Veränderung unseres Bewußrseins, ohne die unsere Gesellschaft ihre notwendigen Veränderungen nicht zustande bringt. 
3. Zur Debatte steht im Zusammenhang mit den politischen Demonstrationen also vor allem das Verhältnis der gegebenen liberalcn Offentlichkeit zur aufgegebenen demokratischen Offentlichkeit. Die liberale Offentlichkeir war am philosophischen law of opinion and reputation orientiert und zielte auf Konsensusbildung der in ihren Interessen homogenisierten bürgerlichen Gesellschaft, deren Selbstverständigung sie diente und für deren Willensbildung Parlament und Geserz die institutionellen Rahmen darstellten. Diese Grundlagen sind in unserer demokratischen Gesellschaft dahin. Der liberal-individualistische Begriff von öffentlicher Meinungsbildung diente den zur staatsfreien Gesellschaft konstituierten Privatleuten als Herrschaftsabwehr und Herrschaftsveränderung. Sie verbürgte »Freiheit « auf der Basis ihrer beiden Hauptbedingungen: Einflußlosigkeit des Staates ("Zensurfreiheit $«$ ) und private Organisation der Medien. So fand öffentliche Meinung den Anschluß an das angeblich unpolitische System der Marktkonkurrenzen. Deshalb noch heute z. B. die wetrbewerblichen Träume etwa der Günther-Presse-Kommission. Sie steuern das Problem notwendig auf Abstellgleise. Denn Freiheit vom Staat verbürgt heute politische Freiheit nicht. Demokratische Offentlictkeit kann sich deshalb nicht mehr in Parlamentarismus und staatsfreier Presse erschöpfen. Sie läßt sich auch nicht identifizieren mit hierarchisierten Repräsentationsmeinungen, mit parteien-mediatisierten Mehrheitsentscheidungen oder sozial-psychologischer Empirie. Sie muß vielmehr zielen auf politische Kommunikation. Dazu gehören heute kritische Analyse, soziale Technologie und rationale Politik (= Bedeutung der Wissenschaft, die in ihrer öffentlichen Wirkung allein die tödliche Alternative von politischem Dezisionismus und irrationaler Technokratie zu durchbrechen vermag) nicht weniger als Konfliktsaustragung und Konsensusbildung in öffentlicher Kontroverse, die nicht zuletzt Verbürgerung von Publizität, Transparenz allen politisch relevanten $\mathrm{Ge}$ schehens (in der Gesamtgeselischaft wie in Teilgesellschaften (z. B. Universität, Großunternehmen, Verbänden usw.)) voraussetzen. Demokratische Pressefreibeit setzt folglich nicht so sehr Vielfalt von Produkten voraus, als vielmehr Gewährleistung notwendiger inhaltlicher Information. Durch vermachtete Informationsämter und Nachrichtenagenturen, durch blockierte Informationsansprüche, durch politische Drohungen gegen unbotmäßige Fernsehanstalten mit der Zulassung privater Fernsehgesellschaften, durch ökonomische Abhängigkeit der Presse von Werbemärkten, durch politisch fungierende "Selbstkontrollen " wird diese Gewährleistung weitaus stärker beeinflußt als z. B. durch verlegerische Marktanteile oder gar kurzfristige Blodkaden von Verlagshäusern und Drudkereien. Wer also z. B. seine Arbeit nicht auf politische Herrschaftsverbältnisse in unserer res publica richtet, mithin nicht untersucht, wie öffentliche Meinung und Pressefreiheit von Problemen der Herrschaftsabwehr gegenüber ökonomisch und politisch Mächtigen zum Problem der Herrschaftsverfestigung der ökonomisch und politisch Mächtigen geworden sind, wer z. B. in „Springer « Eigentum- und Marktprobleme eines an sich privatwirtschaftlichen Konzerns sieht und nicht die Mentalitätsstrukturen von Konzernredaktionen, die politisch wirksame Märkte der Massenpublizistik mit Befriedigung und zugleich Förderung standardisierter Leserbedürfnisse produzieren, wer z. B. nicht begreift, daß Pressefreiheit heute weniger ein Problem der bestehenden Presse als z. B. der unmöglichen Kommunikationsentfaltung etwa einer kritischen Opposition darstellt, der kuriert nur an Symptomen herum. Hier zeigt sich auch, daß z. B. die "Osterunruhen ${ }_{1} 1968$ materialiter als Inanspruchnahme von "Pressefreiheit $\propto$ interpretierbar sind und entsprechenden Grundgesetzschutz genießen. Denn das essentielle Leiden der Presse- und Meinungsfreiheit heute ist nicht weniger und nicht mehr als die 
${ }_{13} 8$ demokratische Organisation unserer politischen Gesellschaft selbst. Soweit hier liberal-individualistische, privat-kapitalistische Systemansätze wichrige Existenzbedingungen der Gesellschaft nicht mehr verbürgen, werden sie illegitim. Legitim werden dann allein gesellschaftliche Ansätze. Sie lassen sich nicht in abstrakten Alternativen zum status quo schaffen, sondern allein in theoriegeleiteter Widerspruchspraxis. An solchen Maßstäben sind politische Demonstrationen zu messen, an ihnen aber haben sie sich auch zu legitimieren.

4. Politisch legitimierte Auseinandersetzung ist folglich zensurfrei zu gewährleisten. Eine Zensur steht ausschließlich einer politisch fungierenden Offentlichkeit selbst zu. Uns daran zu gewöhnen, heißt vor allem, uns falsche Gewalt- und Gewaltlosigkeitmentalitäten abzugewöhnen. Karnevalssessionen mit allen ihren Störungen und "Gewalttätigkeiten « hat die Gesellschaft internalisiert. Nicht daß wir Demonstrationen als Karneval empfinden, ist eine nodi unerfüllte Aufgabe, sondern daß wir sie wie Karneval als selbstverständliche Erschcinungsformen gesellschaftlichen Lebens begreifen und auf uns wirken lassen. Daß Demonstrationen Konflikte z. B. nicht auslösen können, sondern gerade deurlich machen, daß angebliche "Macht« der Demonstranten gerade Ohnmacht sein kann, weil natürlicher und politischer Gewaltbegriff selbstverständlich auch ihrerseits politische Funktionen haben, daß wirklich Mächtige nicht zu demonstrieren brauchen, sondern buchstäblich "gewaltig« herrschen per produzierbare Zustimmung der Beherrschten; daß Demonstranten gute Ordnung und Menschenwürde und Freiheit nicht schon per se verletzen, freilich auch nicht schon per se herbeiführen, kurzum, daß wir Demonstrationen politisch-demokratisch würdigen, nicht individualistisch privatrechtlich, ist unser Problem.

5. Für das Schadensersatzrecht liegen einige Folgerungen auf der flachen Hand: a) Vermögensschutz jenseits des globalen Schutzes gemäß $\int 826$ BGB und des kanalisierten Schutzes gemäß $\{823$ II BGB kennt das deutsche Recht nicht. $\mathrm{Da}$ das Unternehmensrecht auf anderen Feldern tot ist, kann es auf dem unmittelbar verfassungsrechtlich-politischen Felde erst recht nicht leben. Den verfassungswidrigen Schutz des Unternehmens gegenüber Streik und öffentlicher Kritik im politischen Recht öffentlicher Demonstrationen zu kopieren, hieße spezielle Verfassungswidrigkeit durch generelle Verfassungswidrigkeit zu krönen. Es geht deshalb schadenersatzrechtlich folglich auch nicht etwa um grundsätzliche Unrechtsindikation von Demonstrationsgeschehen und ausnabmsweise Rechtfertigung soichen Unrechts, sondern lediglich um unerträgliche Exzesse im Sinnè von $\$ 826$ BGB (ähnlich der bösartigen und gehässigen Schmähkritik als Grenze im Pressedeliktsrecht). In $\$ 826$ BGB ist Sittenwidrigkeit als Verfassungswidrigkeit zu interpretieren. In $\$ 8_{23}$ II BGB müssen alle Schutznormen ebenfalls an der Verfassung gemessen werden.

b) Natürlich sind Vermögensverluste für die Betroffenen - auch diesseits von SS 823 II und 826 BGB - schmerzlich. Hier ist in Anlehnung an Rechtsgrundsätze z. B. über Sonderopfer an anderer Stelle an öffentlichen Entschädigungsschutz ("Tumultschadengesetze «!) zu denken. Für Naturschäden im weitesten Sinne haben wir längst allgemeinen Versicherungsschutz begründet. Wir haben Gefährdungshaftungssysteme, wo immer der Fortschritt Gefahren unvermeidlich macht, und finanzieren sie über Versicherungssysteme. Es ist Zeit, daß wir für - Politikschäden ähnlichen Schutz konzipieren und finanzieren. $\mathrm{Da} B$ wir bisher nicht auf solche Gedanken gekommen sind, liegt eben daran, daß wir die Gesellschaft als pazifiziert, »zivilisiert $\propto$, diszipliniert ansehen. Nur hat diesen $\gg$ Frieden " bis 1918 der Obrigkeitsstaat verbürgt und nach 1933 der totale Staat. In der Weimarer Republik disziplinierten zusehends die "Rechten * die "Linken «, 
nicht zuletzt mit Hilfe von Polizei und Justiz. Es scheint, wie wenn wir heute weder aus dem 19. noch aus dem 20. Jahrhundert zu lernen bereit wären.

c) Die Entwicklung des Unternchmensschutzes im Presse- und Boykottrecht zeigt deutlich, daß, je politischer die Auseinandersetzungen werden, um so stärker der Individualvermögensschutz zurücktreten muß. Die Entscheidung etwa für eine große oder kleine Regierungskoalition berührt schließlich die Vermögensinteressen nahezu aller Bürger niche weniger massiv als z. B. der Ankauf von Flugzeugen Typ Starfighter oder Typ Phantom oder die Ausdehnung von Entwidklungshilfe, die Rüstungssteigcrung usw. In politischen Auseinandersetzungen gelten ausschließlich politische Legitimationsmaßstäbe. Gefängnis und Schadenersatz sind hier oft reine Entpolitisierungsstrategien.

\section{Ergebnis:}

Demonstration, Protest und Widerstand sind auch im Schadenersatzrecht in politischen Zusammenhängen unserer gesellschaftlichen Lage und Entwidklung zu würdigen. Demonstrationen als politische Aufklärung können sich nicht mit dem „Geber im stillen Kämmerlein « begnügen, das für verklungene Freiheitsrechte geradezu typisch ist. $\mathrm{DaB}$ Demonstrationen vielleicht ohne Aussicht auf wirkliche Veränderung der Gesellschaft sind, darf ihre Funktion der legitimierten politischen Fragestellungen weder auf ihre Funktion als reines Alibi verkürzen noch auf ihre Position als Minderheitsopfer einer mit Gefängnis und Schadenersatz reagierenden Gesellschaftsadministration. Beliebte Sätze wie z. B.: Demonstration ja, aber in Ruhe und Ordnung; Kritik ja, aber in korrekten Formen; wir leben in einer freiheitlichen Demokratie, aber auch in einem Rechtsstaat (welche Vorstellung vom Verhälenis von Freiheit und Recht!), reduzieren den politischen Gehale einer modernen Gesellschaft und ihrer Verfassung auf die liberal-individualistische Besitz- und Bildungsbürgergesellschaft der historischen Rechtsschule, indem sie unter Berufung auf die gleichbleibend-zeitlose Funktion der Rechtsformen für die Verbürgung von Freiheit und Gleichheit in Wahrheit nämlich eben jene Rechtsinhalte erhalten, die einst, als die Formenfunktion sich durchsetzte, in jene Formen eingeflossen sind. 